\title{
Erratum: A novel cancer immunotherapy based on the combination of a synthetic carbohydrate-pulsed dendritic cell vaccine and glycoengineered cancer cells
}

\section{Lei Qiu, Jie Li, Shichong Yu, Qianli Wang, Yinghua Li, Zhenlin Hu, Qiuye Wu, Zhongwu Guo, Junping Zhang}

Oncotarget. 2015; 6:5195-5203

PMID: 25760071

Present:

\section{FINANCIAL SUPPORT}

This work was supported by the National Natural Science Foundation of China (No.30728032, 21202200).

Correct:

FINANCIAL SUPPORT

This work was supported by the National Natural Science Foundation of China (No.30728032, 21202200) and R01 CA095142/CA/NCI NIH HHS/United States. 